\title{
Thrombin generation and fibrin clot structure after vitamin D supplementation
}

\author{
Marc Blondon ${ }^{1}$, Emmanuel Biver ${ }^{2}$, Olivia Braillard ${ }^{3}$, Marc Righini' ${ }^{1}$, Pierre Fontana ${ }^{1}$ and Alessandro Casini ${ }^{1}$ \\ 'Division of Angiology and Hemostasis, Geneva University Hospitals and Faculty of Medicine, University of Geneva, Geneva, Switzerland \\ ${ }^{2}$ Division of Bone Diseases, Geneva University Hospitals and Faculty of Medicine, University of Geneva, Geneva, Switzerland \\ ${ }^{3}$ Division of Primary Care Medicine, Geneva University Hospitals and Faculty of Medicine, University of Geneva, Geneva, Switzerland
}

Correspondence should be addressed to M Blondon: marc.blondon@hcuge.ch

\begin{abstract}
Objective: Vitamin D deficiency is associated with increased risks of arterial and venous cardiovascular events. Hypothetically, supplementation with vitamin D may lead to a less prothrombotic phenotype, as measured by global coagulation assays and fibrin clot structure.

Methods: In this prospective cohort study, we enrolled adult outpatients attending the Primary Care Division of the Geneva University Hospitals with a severe vitamin D deficiency (25-hydroxyvitamin-D3 (25-OHD) <25 nmol/L), excluding obese patients or with a recent acute medical event. We evaluated changes in coagulation times, thrombin generation assay, clot formation and clot lysis time, 25-OHD and parathormone before and 1-3 months after cholecalciferol oral supplementation with one-time 300,000 IU then 800 IU daily. Paired $t$-tests with a two-sided alpha of 0.05 compared absolute mean differences.

Results: The 48 participants had a mean age of $43.8 \pm 13.8$ years. After supplementation, $25-\mathrm{OHD}$ levels increased from $17.9 \pm 4.6 \mathrm{nmol} / \mathrm{L}$ to $62.5 \pm 20.7 \mathrm{nmol} / \mathrm{L} 6.4 \pm 3.0$ weeks after inclusion. Endogenous thrombin potential and thrombin generation peak values both decreased significantly $(-95.4 \mathrm{nM} \times \min (95 \% \mathrm{Cl}-127.9$ to -62.8$), P<0.001$; $-15.1 \mathrm{nM}(-23.3$ to -6.8$), P<0.001)$. The maximum absorbance by turbidimetry decreased significantly $(P=0.001)$ after supplementation. There was no change in clot lysis time, coagulation times or plasminogen activator inhibitor-1 and homocysteine levels. Conclusions: In severe vitamin D deficiency, a high-dose cholecalciferol supplementation was associated with a reduction in thrombin generation and an average decreased number of fibrin protofibrils per fibers and fibrin fiber size measured by turbidimetry. This suggests that severe vitamin $\mathrm{D}$ deficiency may be associated with a potentially reversible prothrombotic profile.
\end{abstract}

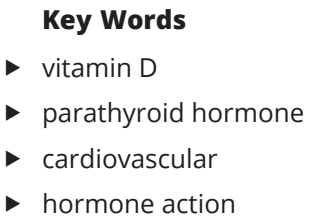

Endocrine Connections (2019) 8, 1447-1454

\section{Introduction}

Thrombosis, collectively including ischemic heart disease, stroke and venous thromboembolism (VTE), causes more than one in four deaths worldwide (1). Venous thromboembolism itself is among the largest contributor of loss of disability-adjusted life-years in both high- and low-income countries. With this massive burden, prevention efforts may yield important positive effects on the population's health.

In observational studies, vitamin D deficiency is associated with increased future risks of arterial cardiovascular disease (CVD) and, perhaps, of VTE (2, $3,4)$. In contrast, vitamin D interventional studies have not demonstrated a protective role of cholecalciferol 
supplementation on cardiovascular health $(5,6,7)$. Given that such randomized studies were set among generally healthy adults, and with the expected healthier status of trial participants, severe vitamin D deficiency (as defined by 25 -hydroxyvitamin (25-OHD) levels $<25-30 \mathrm{nmol} / \mathrm{L}$ ) was under-represented in these trials. However, the high prevalence of severe vitamin D deficiency highlights its public health relevance, because about 1 in 7-8 European citizens suffer from this condition (8).

While several mechanisms linking vitamin D with CVD have been studied, whether vitamin D deficiency or supplementation affects hemostasis remains largely unexplored. Previous studies have reported cross-sectional associations of 25-OHD levels with tissue plasminogen activator (tPA), thrombin generation, plasminogen activator inhibitor-1 (PAI-1) and tissue factor pathway inhibitor (TFPI) $(9,10,11)$, building on previous in vitro reports of a prothrombotic environment in vitamin D deficiency $(12,13)$. Three cohorts have studied the influence of vitamin D supplementation on thrombin generation, a global measure of hemostasis, and have led to contradictory results $(11,14,15)$. The fibrin clot structure, which has not been studied in relationship to vitamin $\mathrm{D}$, is a major determinant of the mechanical properties of the clot and its resistance to fibrinolysis, and appears altered in a variety of diseases of thrombotic or hemorrhagic phenotypes $(16,17)$.

We hypothesized that supplementation with vitamin $\mathrm{D}$ in deficient patients would be associated with a less prothrombotic hemostatic profile, as measured by thrombin generation and fibrin clot structure, and tested this in a prospective cohort of outpatients with severe 25-OHD deficiency.

\section{Material and methods}

This prospective cohort was set in the Primary Care Clinic of the Geneva University Hospitals, from June 2016 to June 2017. The study was approved by the Ethics Committee (Commission cantonale d'éthique de la recherche de Genève, 2016-00124), and informed consent was obtained from all participants after full explanation of the purpose and nature of all procedures used.

\section{Population}

We screened the results of all measurements of 25-OHD performed in adult outpatients. Vitamin D status is evaluated routinely in clinical practice at the first medical encounter and in follow-ups, when deemed necessary.
Inclusion criteria were an age $\geq 18$ years and severe vitamin D deficiency defined as a level of $25-\mathrm{OHD}<25 \mathrm{nmol} / \mathrm{L}$ $(10 \mathrm{ng} / \mathrm{mL})$. Exclusion criteria were an ongoing treatment with anticoagulant or calcium/vitamin D supplements, an active cancer (diagnosed within 5 years or treated within 2 years), renal insufficiency (eGFR $<30 \mathrm{~mL} / \mathrm{min}$ ), a primary hyperparathyroidism, any malabsorption disease, an active inflammatory disease, a recent infection, surgery or hospitalization ( $<30$ days), obesity (BMI $>30 \mathrm{~kg} / \mathrm{m}^{2}$ ), a recent thromboembolic or cardiovascular event ( $<90$ days), or an ongoing pregnancy.

\section{Vitamin D supplementation}

Following local recommendations for supplementation in patients with vitamin D deficiency, all participants received a one-time high-dose oral cholecalciferol (300,000 IU) delivered directly at the Clinic, and a prescription for oral cholecalciferol (800 IU daily), without calcium supplement. This regimen had been recommended in the context of poor adherence to daily or weekly low doses of vitamin $\mathrm{D}$ in this population.

\section{Data collection, variables and outcomes}

Participants were evaluated at baseline, shortly after the diagnosis of vitamin D deficiency, to collect data on demographics, medical history and a blood sample was collected through a peripheral phlebotomy. One to three months after inclusion and after the start of vitamin D supplementation, participants were invited for the second blood collection.

Most variables, including race, smoking, fractures, and menopause status, were self-reported. The electronic medical chart, including all laboratory results, was extracted to evaluate for the presence of co-morbidities and prescribed medications. Blood pressure and BMI were measured at baseline.

The primary outcome of the study was the change in thrombin generation biomarkers (endogenous thrombin potential (ETP)) and fibrin clot structure measurements (clot lysis time and maximal absorption by turbidimetry). As secondary outcomes, we also measured levels of PAI-1 and homocysteine, given previously reported crosssectional associations with 25-OHD levels (9).

\section{Blood analyses}

Non-fasting blood samples were collected into a tube containing 0.109 M citrate (BD Vacutainer, Plymouth, UK)

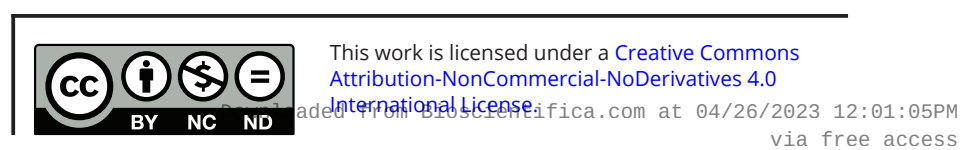


after having discarded the first few milliliters. Blood was processed and centrifuged rapidly after collection, within at most $90 \mathrm{~min}$. Routine analyses, including 25-OHD, calcium, PTH levels and coagulation times, were performed at the time of blood draw. All other assessments were performed batchwise by the same laboratory technician who was blind to the time of sampling (pre or postsupplementation), on plasma samples frozen on average for $48 \pm 24$ days after a double centrifugation procedure $(2000 \boldsymbol{g}$ for $10 \mathrm{~min}$ then $3900 \boldsymbol{g}$ for $10 \mathrm{~min}$ ). Coagulation assays were performed on a BCS-XP (Siemens) automate, using Pathromtin SL (Siemens) for the activated partial thromboplastin time (aPTT) and Innovin (Siemens) for the prothrombin time (PT). Plasma level of functional fibrinogen was measured by the Clauss method using thrombin $100 \mathrm{IU} / \mathrm{mL}$ (Siemens). 25-OHD levels and PTH were measured by an electro-chemiluminescence-binding assay using the COBAS automate (Roche). Serum calcium was analyzed by photometrical assay (Roche).

Thrombin generation assay was performed with the calibrated automated thrombography (CAT) method (Stago, Asnières, France) by use of a flurometer (Fluroscan Ascent; ThermoLab Systems, USA) equipped with a dispenser (18). Coagulation was initiated with $5 \mathrm{pM}$ of tissue factor and $4 \mu \mathrm{M}$ of phospholipids (PPP reagent, Stago). Calibration for each patient was performed with Thrombin Calibrator (Stago). All plates were incubated at $37^{\circ} \mathrm{C}$ for $10 \mathrm{~min}$ before addition of the fluorogenic substrate and calcium chloride $\left(\mathrm{CaCl}_{2}\right.$; FluCa-Kit, Stago), and tests were performed in triplicate. Raw data were analyzed with Thrombinoscope V5 (Stago).

Pre- and post-supplementation fibrin polymerization and fibrinolysis were assessed by turbidity assays on plasma (19). Plasma samples were diluted $1 / 6$ with TBS (50 $\mathrm{mM}$ Tris, $100 \mathrm{mM} \mathrm{NaCl}, \mathrm{pH}$ 7.4). Fibrin polymerization was monitored at $405 \mathrm{~nm}$ every $8 \mathrm{~s}$ for $120 \mathrm{~min}$ using a microplate reader (VersaMax, Molecular Devices, USA), after incubation with $0.1 \mathrm{U} / \mathrm{mL}$ human thrombin (Merck $\mathrm{KGAa}$, Germany) and $5 \mathrm{mM} \mathrm{CaCl}_{2}$ (final concentrations) in a final volume of $150 \mu \mathrm{L}$. Fibrinolysis (clot lysis time) was evaluated by adding $85 \mathrm{ng} / \mathrm{mL}$ of tPA (Technoclone $\mathrm{GmbH}$, Austria) to aim at clot lysis time of about $20 \mathrm{~min}$ (20). The inter-assay and intra-assay coefficients of variability were 4.7 and 5.4\%, respectively. All measurements were made in triplicate and processed with the SoftMAX Pro software. Briefly, the maximum absorbance of the growing clot will reflect the average fibrin fiber size and the number of protofibrils per fiber. The clot lysis time corresponds to the time from the threshold of $50 \%$ of the maximum clot polymerization to the threshold of $50 \%$ of fibrinolysis and determines the overall fibrinolytic properties of the clot. All turbidimetry data were analysed with the Shiny App tool (21).

\section{Statistical analyses}

Baseline variables were summarized as mean (s.D.) and proportions.

Hemostatic biomarkers were evaluated as arithmetic means (s.D.). In the primary analysis, we tested for differences in measurements before and after supplementation with vitamin D using paired $t$-tests, therefore estimating the mean absolute change between those 2 times. Relative differences in geometric means were also reported. In secondary analyses, the absolute change in 25-OHD measurements after supplementation was correlated to the absolute change in hemostatic measurements, using linear regression. Finally, we also explored the following subgroups: according to baseline 25-OHD levels (in tertiles), baseline PTH levels (secondary hyperparathyroidism vs not), age ( $<43$ vs $\geq 43$ years), sex and co-morbidities (hypertension, diabetes and/or cardiovascular disease).

There was a minimal amount of missing values, and no imputation was performed. Outliers were assessed graphically and excluded in sensitivity analyses to assess their impact on the primary findings. We also repeated the primary analyses with a permutation test for comparison of means (no assumption of the distribution of data) instead of $t$-tests, without any difference in statistical differences.

Statistical significance was set at an alpha level of 0.05. All analyses were conducted on Stata 11 (StataCorp).

\section{Results}

From June 2016 to June 2017, we screened 2015 measurements of 25-OHD, of which 363 were $<25 \mathrm{nmol} / \mathrm{L}$ (prevalence of $18 \%$ ). After exclusion, mostly because of ongoing supplementation of vitamin D or obesity, 55 participants were included, of whom 48 completed the study (Fig. 1).

The 48 participants had a mean age of 44 years (range 23-74 years) and were of diverse race/ethnicity (Table 1). 25/48 had at least one cardiovascular risk factor. One participant had a history of CVD, and none of VTE.

Vitamin D supplementation increased mean levels of 25-OHD significantly and greatly, from $17.9 \mathrm{nmol} / \mathrm{L} \pm 4.6$ to $62.5 \mathrm{nmol} / \mathrm{L} \pm 20.7(P<0.0001)$, after an average of $6.4 \pm 3.0$ weeks of study time (Table 2). The increase in 


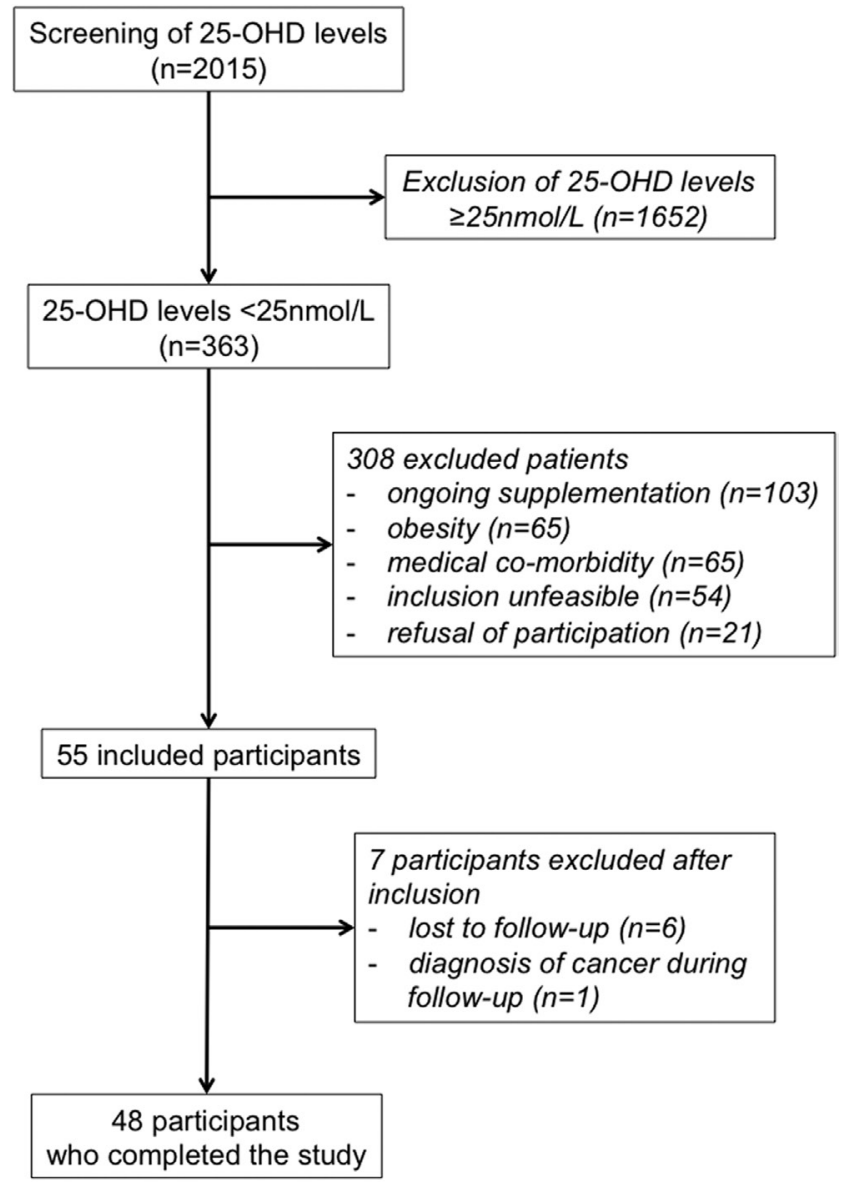

Figure 1

Flow-chart of the study.

25-OHD levels ranged from $7 \mathrm{nmol} / \mathrm{L}$ to $99 \mathrm{nmol} / \mathrm{L}$. While all participants had severe baseline deficiency $(<25 \mathrm{~mol} / \mathrm{L})$, at follow-up 12 had normal levels ( $\geq 75 \mathrm{nmol} / \mathrm{L}), 23 \mathrm{had}$ insufficient levels (50-75 nmol/L), 12 had deficient levels (25-50 nmol/L) and 1 had persistent severely deficient levels. PTH levels decreased accordingly. 26/48 and 12/48 had secondary hyperparathyroidism, defined as PTH $>6.8$ $\mathrm{pmol} / \mathrm{L}$, at baseline and at follow-up, respectively. Serum calcium remained unchanged at normal values.

We observed differences in thrombin generation measurements, after supplementation with cholecalciferol (Table 2). Mean endogenous thrombin potential (ETP) was decreased by $95.4 \mathrm{nM} \times \min (95 \% \mathrm{CI}-128.9$ to $-62.8, P<0.001)$, corresponding to a relative reduction of geometric means of $6.8 \%$ (95\%CI 4.6-9.0). Peak values were smaller $(-15.1 \mathrm{nM}, 95 \% \mathrm{CI}-23.3$ to $-6.8, P<0.001)$ and both the lag time and the time to peak increased after supplementation. In turbidimetry assays, the maximum clot density was lower after supplementation, with a relative reduction of geometric means of $8.5 \%$ (95\% CI
-13.1 to -3.6$)$. One participant had a large reduction of ETP (25.2\%) after supplementation. Excluding this possible outlier did not affect the results or their statistical significance.

Measurements of fibrinolysis were unchanged after supplementation, including both clot lysis time and the AUC of fibrinolysis (data not shown). Coagulation times (PT and aPTT) and levels of fibrinogen, PAI-1 and homocysteine levels remained stable during the study (Table 2).

Neither the absolute nor the relative change of ETP was related to the absolute continuous change in 25-OHD levels, in univariate analysis $(P=0.43$ and $P=0.48$, respectively). In subgroup analyses, we explored the absolute change of ETP across tertiles of magnitude of change of 25-OHD levels (Fig. 2A) and between participants with normal and elevated baseline PTH (secondary hyperparathyroidism, Fig. 2B), without suggestion of effect modification. Similarly, there was no modification of the positive findings for ETP in subgroups of age, sex and co-morbidities (data not shown).

During the study time, no participants suffered from a cardiovascular or VTE event or changed their co-medication apart from vitamins in a few.

\section{Discussion}

In this prospective cohort of outpatients with severe vitamin D deficiency, the supplementation with high-dose calcidiol was associated with reduced in vitro thrombin generation and decreased clot density, without change in fibrinolytic times. These findings may suggest that vitamin D supplementation decreases a prothrombotic profile induced by severe vitamin D deficiency.

Three other studies evaluating changes in thrombin generation after calcidiol have generated conflicting findings, including two negative studies. In a Norwegian clinical trial, 158 obese participants were randomized to 40,000 IU of weekly cholecalciferol or placebo supplementation for 12 months. In the vitamin D group, mean 25-OHD levels increased from 61.8 to 145.5 $\mathrm{nmol} / \mathrm{L}$ (11). The observed lack of change in thrombin generation in this study may come from the selection of obese patients without a vitamin D deficiency at baseline. The second negative study was a recent Dutch prospective cohort, in whom 59 patients with severe 25-OHD were treated with a 2-month oral cholecalciferol supplementation of 900,000 IU. While the 25-OHD levels increased dramatically from $20 \mathrm{nmol} / \mathrm{L}$ to an average of

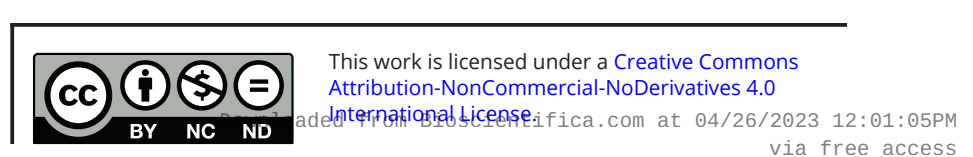


Table 1 Baseline characteristics of the participants $(n=48)$.

\begin{tabular}{|c|c|}
\hline Baseline characteristics & $\boldsymbol{n}$ or mean (S.D.) $(n=48)^{\mathbf{a}}$ \\
\hline Men & 21 \\
\hline Age, years & $43.8(13.8)$ \\
\hline \multicolumn{2}{|l|}{ Race } \\
\hline White & 17 \\
\hline Hispanic white & 19 \\
\hline Black & 7 \\
\hline Asian & 5 \\
\hline $\mathrm{BMI}, \mathrm{kg} / \mathrm{m}^{2}$ & $24.2(3.4)$ \\
\hline Current smoker & 14 \\
\hline Diabetes & 6 \\
\hline Hypertension & 11 \\
\hline Mean SBP/DBP, mmHg & $124 / 76(16 / 10)$ \\
\hline Cardiovascular disease & 1 \\
\hline Prior fracture & $9^{a}$ \\
\hline \multicolumn{2}{|l|}{ Current use of } \\
\hline Anti-hypertensive & 12 \\
\hline Statins & 7 \\
\hline Folates & 7 \\
\hline Estrogenic contraceptive & 0 \\
\hline Progestogen-only contraceptive & 4 \\
\hline CKD-EPI GFR, mL/min & $107(17)$ \\
\hline Hemoglobin, g/L & $138.7(16.5)^{\mathrm{b}}$ \\
\hline Platelets, G/L & $287.8(66.1)^{\mathrm{b}}$ \\
\hline Prothrombin time, $\%^{c}$ & $92.3(8.6)$ \\
\hline aPTT, $\mathrm{s}^{\mathrm{c}}$ & $30.0(3.2)$ \\
\hline Fibrinogen, g/Lc & $3.1(0.7)$ \\
\hline
\end{tabular}

${ }^{\mathrm{a}} 1$ and ${ }^{\mathrm{b}} 7$ missing values; ${ }^{\mathrm{c}}$ Normal ranges: Prothrombin time $>70 \%$, aPTT 26-37 s, fibrinogen 1.5-3.5 g/L.

$108 \mathrm{nmol} / \mathrm{L}$, thrombin generation parameters and clot lysis time remained similar (15). Our discrepant positive results may arise from a stricter selection of participants without active cardiovascular disease (albeit with cardiovascular risk factors) and antithrombotic drugs, and a different condition of the thrombin generation assay (using $5 \mathrm{pM}$ of tissue factor). A third study treated 53 Israeli healthy volunteers with $25-\mathrm{OHD}<50 \mathrm{nmol} / \mathrm{L}$ with $2000 \mathrm{IU}$ of daily cholecalciferol supplementation for 90 days, increasing their mean 25-OHD levels from 32 to $52 \mathrm{nmol} / \mathrm{L}$. Contrary to our findings, thrombin generation was greater after supplementation, with greater ETP and peak levels (14). We hypothesize, given this body of evidence, that a reversible prothrombotic hemostatic environment may only be observed in patients with severe vitamin D deficiency (25-OHD levels $<25 \mathrm{nmol} / \mathrm{L}$ ), without primary hyperparathyroidism or CVD, who were specifically included in our cohort. This hypothesis may be supported by the secondary analyses of the Women's Health Initiative, in which supplementation with 400 IU of daily vitamin $\mathrm{D}$ and calcium reduced the risk of VTE in the small subgroup of women with $25-\mathrm{OHD}<25 \mathrm{nmol} / \mathrm{L}$, although this may have been a chance finding (3).

In the general population, two recently published large trials have demonstrated the lack of influence of cholecalciferol supplementation on arterial cardiovascular events. The VITAL study randomized 25,871 American $>50-55$ years old participants to 2000 IU of cholecalciferol or placebo (6). A New Zealander study randomized 5110 $>50$ years old participants to 200,000 IU then 100,000 IU monthly of cholecalciferol or placebo (7). No changes in the risk of major cardiovascular outcomes were noted after median follow-ups of 5.3 and 3.3 years, respectively.

Table 2 Mean levels of mineral metabolism and hemostatic biomarkers before and after supplementation.

\begin{tabular}{l}
\hline \\
\hline $25 \mathrm{D}, \mathrm{nmol} / \mathrm{L}$ \\
$\mathrm{PTH}, \mathrm{pmol} / \mathrm{L}$ \\
Calcium, mmol/L \\
Thrombin generation \\
ETP, nM $\times$ min \\
Peak, nM \\
Lag time, min \\
Time to peak, min \\
Fibrinolysis \\
Clot lysis time, min ${ }^{\mathrm{a}}$ \\
Fibrin polymerization \\
Maximum absorbance, OD ${ }^{\mathrm{a}}$ \\
Other \\
Prothrombin time, \% \\
aPTT, s \\
Fibrinogen activity, g/L \\
PAl-1 \\
Homocysteine ${ }^{\mathrm{b}}$
\end{tabular}

\begin{tabular}{c}
\hline Baseline (s.D.) \\
\hline $17.9(4.6)$ \\
$7.6(2.9)$ \\
$2.29(0.08)$ \\
$1384.3(218.4)$ \\
$221.5(46.5)$ \\
$2.99(0.50)$ \\
$6.41(0.98)$
\end{tabular}

\begin{tabular}{c}
\hline After supplementation (s.D.) \\
\hline $62.5(20.7)$ \\
$6.2(2.5)$ \\
$2.29(0.08)$ \\
\\
$1288.9(197.2)$ \\
$206.5(45.7)$ \\
$3.24(0.53)$ \\
$6.63(0.92)$
\end{tabular}

\begin{tabular}{c} 
Absolute difference $(95 \% \mathrm{Cl})$ \\
\hline$+44.5(+38.8$ to +50.3$)$ \\
$-1.4(-0.7$ to -2.1$)$ \\
$0.00(-0.02$ to 0.02$)$ \\
$-95.4(-127.9$ to -62.8$)$ \\
$-15.1(-23.3$ to -6.8$)$ \\
$+0.25(+0.12$ to +0.37$)$ \\
$+0.22(+0.03$ to +0.41$)$
\end{tabular}

\begin{tabular}{c}
\hline P value \\
\hline$<0.001$ \\
$<0.001$ \\
0.72
\end{tabular}

$16.6(5.5)$

$17.0(6.6)$

$0.43(0.08)$

$0.40(0.08)$

$+0.4(-1.3$ to +2.1$)$

$<0.001$

$<0.001$

$<0.001$

0.027

$92.3(8.6)$

$30.0(3.2)$

$3.1(0.7)$

$12.9(8.0)$

$14.7(14.8)$
$91.9 \%(8.6)$

$30.0(3.2)$

$3.0(0.7)$

$14.0(13.0)$

$12.0(4.9)$

\begin{tabular}{cc}
$+0.4(-1.3$ to +2.1$)$ & 0.62 \\
$-0.04(-0.06$ to -0.02$)$ & 0.001 \\
$-0.4(-2.2$ to 1.4$)$ & 0.65 \\
$0.0(-0.5$ to 0.5$)$ & 0.95 \\
$0.0(-0.2$ to 0.1$)$ & 0.64 \\
$+1.1(-1.7$ to +3.9$)$ & 0.42 \\
$-2.7(-6.4$ to +1.1$)$ & 0.15 \\
\hline
\end{tabular}

${ }^{\mathrm{a}} n=47 ;{ }^{\mathrm{b}} n=45$.

aPTT, activate partial thromboplastin time; ETP, endogenous thrombin potential; OD, optical density; PAl-1, plasminogen activator inhibitor-1.

(c) 2019 The authors Published by Bioscientifica Ltd

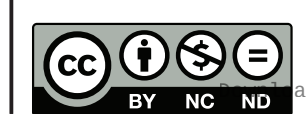

This work is licensed under a Creative Commons Attribution-NonCommercial-NoDerivatives 4.0 Internationab sicense.ifica . com at $04 / 26 / 2023 \quad 12: 01: 05 \mathrm{PM}$ 

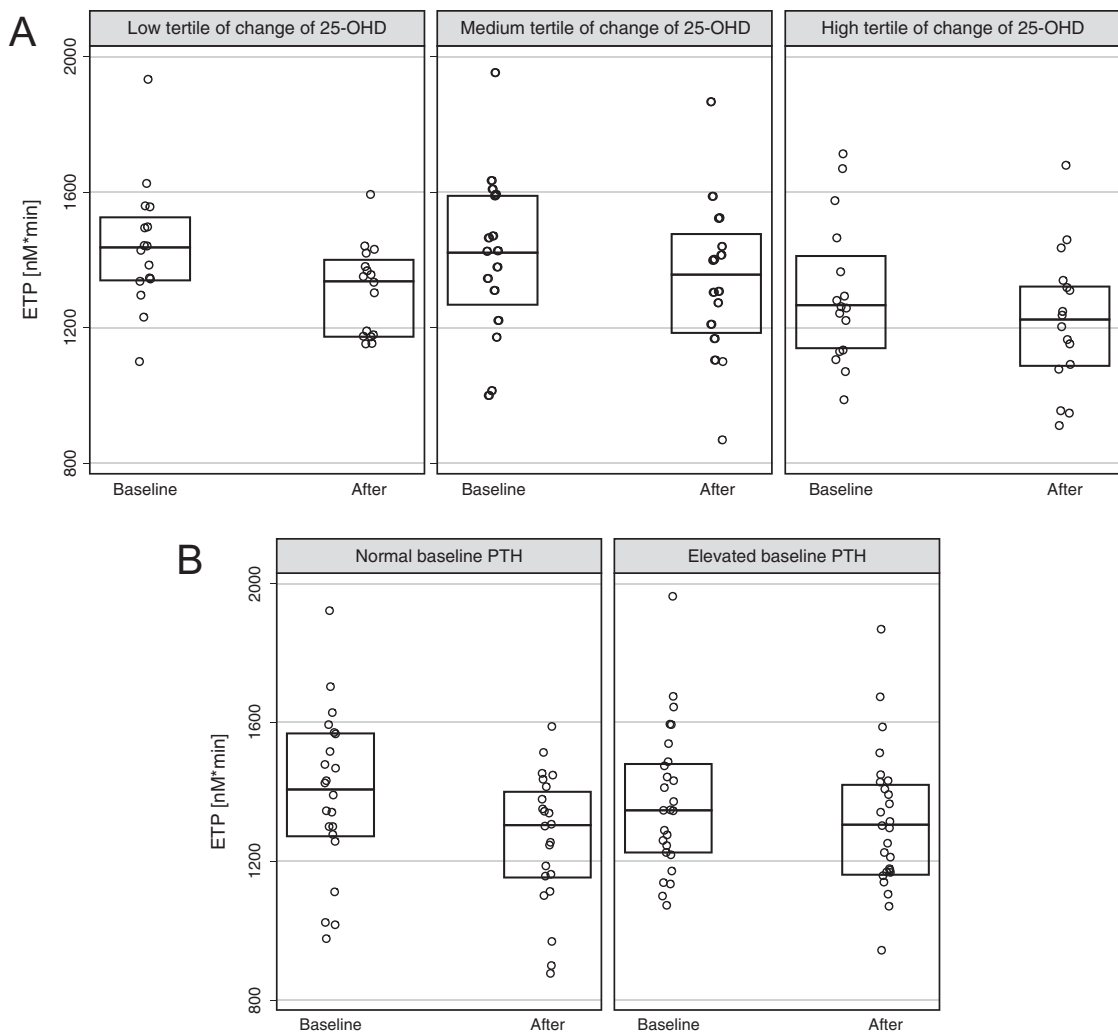

\begin{abstract}
Figure 2
Boxplots (median and 25/75th percentile) of endogenous thrombin potential. (A) In subgroups of tertiles of change of $25-\mathrm{OHD}$ levels over the study period ( $1=7-34 \mathrm{mM} ; 2=35-52 \mathrm{mM}$; $3=53-99 \mathrm{mM}$ ). (B) In subgroups of baseline PTH. Results are statistically different $(P<0.05)$ in all five subgroups.
\end{abstract}

In both studies, vitamin $\mathrm{D}$ deficiency $(<50 \mathrm{nmol} / \mathrm{L})$ was under-represented (12.7 and 30\%), with mean baseline 25-OHD levels of $77 \mathrm{nmol} / \mathrm{L}$ and $64 \mathrm{nmol} / \mathrm{L}$, respectively. Therefore, for severe vitamin D deficiency $(<25 \mathrm{nmol} / \mathrm{L})$, no firm conclusions can be drawn at this point.

The influence of secondary hemostasis (i.e. coagulation) on the risk of atherosclerotic disease is well documented. Anticoagulation with vitamin $\mathrm{K}$ antagonists is an effective secondary prevention of coronary heart disease events, albeit at a cost of bleeding. Recently, the COMPASS trial established the role of low-dose anticoagulants (rivaroxaban), in addition to aspirin, on the risk of cardiovascular death, stroke and myocardial infarction, among participants with stable CVD (22). On top of the clear link to venous thromboembolism, modifications of the hemostatic environment may therefore represent a plausible mechanism explaining an elevated cardiovascular arterial risk associated with severe vitamin D deficiency.

We studied biological endpoints and no conclusive clinical implications should be drawn. Both high thrombin generation and thrombin peak levels are associated with the risk of a first VTE, suggesting that thrombin generation may represent a valid intermediate phenotype $(23,24)$. Whether the $95 \mathrm{nM} \times \min$ or the
$6.8 \%$ decrease in ETP with supplementation translates into fewer VTE events is speculative. As a comparison, the G20210 prothrombin polymorphism causes a 3-fold increased risk of incident VTE and is associated with a $422 \mathrm{nM} \times \min$ or $20 \%$ difference in ETP, using the same thrombin generation assay (25).

Abnormal fibrin clot structure, in particular increased fibrin fiber density and resistance to fibrinolysis are reported to be linked to CVD (16). However, several modulators such as blood cells interactions, blood flow conditions and endothelium can modify the fibrin clot network in vivo (26). It is likely that these effect (e.g. effects of vitamin D on endothelium) are not properly detected by ex vivo studies (27). Similarly, the in vitro capacity of plasma to generate thrombin over time (ETP) reflect of potential thrombin generation that must be distinguished from in vivo markers of thrombin generation such as prothrombin fragments 1 and 2, thrombin anti-thrombin complexes and fibrinopeptide A.

The strengths of our study include the assessment of global hemostasis assays and fibrin clot structure and the restriction to patients suffering from severe vitamin D deficiency, which brings supplementary data to this field. The main limitation of our findings is the lack of control group, which precludes us from drawing any (c) 2019 The authors Published by Bioscientifica Ltd
This work is licensed under a Creative Commons Attribution-NonCommercial-NoDerivatives 4.0 Internationab sicense.ifica . com at 04/26/2023 12:01:05PM 
definite causal conclusions. However, during the short follow-up of our study ( 6.8 weeks), there was almost no new drug prescribed (only vitamins) and no change in contraceptives.

In conclusion, our findings support the concept of a relationship between severe vitamin D deficiency and a prothrombotic phenotype. Given the recent negative evidence from large trials of vitamin D supplementation in the general population, the influence of vitamin D status on hemostasis may be restricted to individuals with a severe vitamin D deficiency.

\section{Declaration of interest}

The authors declare that there is no conflict of interest that could be perceived as prejudicing the impartiality of the research reported.

\section{Funding}

The study was funded by a PRD research grant from the Geneva University Hospital. The authors are grateful to Céline Fickentscher for her technical assistance and Thomas Lecompte for his expertise on thrombin generation assay. P Fontana reports non-financial support from NovoNordisk and Bayer, outside the submitted work. The other authors report no relevant disclosures for this manuscript.

\section{References}

1 ISTH Steering Committee for World Thrombosis Day. Thrombosis: a major contributor to global disease burden. Thrombosis Research 2014 134 931-938. (https://doi.org/10.1016/j.thromres.2014.08.014)

2 Kestenbaum B, Katz R, de Boer I, Hoofnagle A, Sarnak MJ, Shlipak MG, Jenny NS \& Siscovick DS. Vitamin D, parathyroid hormone, and cardiovascular events among older adults. Journal of the American College of Cardiology 201158 1433-1441. (https://doi. org/10.1016/j.jacc.2011.03.069)

3 Blondon M, Rodabough RJ, Budrys N, Johnson KC, Berger JS, Shikany JM, Raiesdana A, Heckbert SR, Manson JE, LaCroix AZ, et al. The effect of calcium plus vitamin D supplementation on the risk of venous thromboembolism. From the Women's Health Initiative randomized controlled trial. Thrombosis and Haemostasis 2015113 999-1009. (https://doi.org/10.1160/TH14-05-0478)

4 Brondum-Jacobsen P, Benn M, Tybjaerg-Hansen A \& Nordestgaard BG. 25-Hydroxyvitamin D concentrations and risk of venous thromboembolism in the general population with 18,791 participants. Journal of Thrombosis and Haemostasis 201311 423-431. (https://doi.org/10.1111/jth.12118)

5 Hsia J, Heiss G, Ren H, Allison M, Dolan NC, Greenland P, Heckbert SR, Johnson KC, Manson JE, Sidney S, et al. Calcium/ vitamin D supplementation and cardiovascular events. Circulation 2007115 846-854. (https://doi.org/10.1161/ CIRCULATIONAHA.106.673491)

6 Manson JE, Cook NR, Lee IM, Christen W, Bassuk SS, Mora S, Gibson H, Gordon D, Copeland T, D'Agostino D, et al. Vitamin D supplements and prevention of cancer and cardiovascular disease. New England Journal of Medicine 2019380 33-44. (https://doi. org/10.1056/NEJMoa1809944)

7 Scragg R, Stewart AW, Waayer D, Lawes CMM, Toop L, Sluyter J, Murphy J, Khaw KT \& Camargo Jr CA. Effect of monthly high-dose vitamin D supplementation on cardiovascular disease in the vitamin
D assessment study: a randomized clinical trial. JAMA Cardiology 20172 608-616. (https://doi.org/10.1001/jamacardio.2017.0175)

8 Cashman KD, Dowling KG, Skrabakova Z, Gonzalez-Gross M, Valtuena J, De Henauw S, Moreno L, Damsgaard CT, Michaelsen KF, Molgaard C, et al. Vitamin D deficiency in Europe: pandemic? American Journal of Clinical Nutrition 2016103 1033-1044. (https:// doi.org/10.3945/ajcn.115.120873)

9 Blondon M, Cushman M, Jenny N, Michos ED, Smith NL, Kestenbaum B \& de Boer IH. Associations of serum 25-hydroxyvitamin D with hemostatic and inflammatory biomarkers in the multi-ethnic study of atherosclerosis. Journal of Clinical Endocrinology and Metabolism 2016101 2348-2357. (https://doi. org/10.1210/jc.2016-1368)

10 Jorde R, Haug E, Figenschau Y \& Hansen JB. Serum levels of vitamin $\mathrm{D}$ and haemostatic factors in healthy subjects: the Tromso study. Acta Haematologica 2007117 91-97. (https://doi.org/10.1159/000097383)

11 Jorde R, Sneve M, Torjesen P, Figenschau Y \& Hansen JB. Parameters of the thrombogram are associated with serum 25-hydroxyvitamin D levels at baseline, but not affected during supplementation with vitamin D. Thrombosis Research 2010125 e210-e213. (https://doi. org/10.1016/j.thromres.2009.12.011)

12 Aihara K, Azuma H, Akaike M, Ikeda Y, Yamashita M, Sudo T, Hayashi H, Yamada Y, Endoh F, Fujimura M, et al. Disruption of nuclear vitamin D receptor gene causes enhanced thrombogenicity in mice. Journal of Biological Chemistry 2004279 35798-35802. (https://doi.org/10.1074/jbc.M404865200)

13 Koyama T, Shibakura M, Ohsawa M, Kamiyama R \& Hirosawa S. Anticoagulant effects of 1alpha,25-dihydroxyvitamin D3 on human myelogenous leukemia cells and monocytes. Blood 199892 160-167. (https://doi.org/10.1182/blood.V92.1.160.413k16_160_167)

14 Saliba W, Awad K, Ron G \& Elias M. The effect of vitamin D supplementation on thrombin generation assessed by the calibrated automated thrombogram. Clinical and Applied Thrombosis/Hemostasis 201622 340-345. (https://doi.org/10.1177/1076029614556745)

15 Elbers LPB, Wijnberge M, Meijers JCM, Poland DCW, Brandjes DPM, Fliers E \& Gerdes VEA. Coagulation and fibrinolysis in hyperparathyroidism secondary to vitamin D deficiency. Endocrine Connections 20187 325-333. (https://doi.org/10.1530/EC-17-0249)

16 Undas A \& Ariens RA. Fibrin clot structure and function: a role in the pathophysiology of arterial and venous thromboembolic diseases. Arteriosclerosis, Thrombosis, and Vascular Biology 201131 e88-e99. (https://doi.org/10.1161/ATVBAHA.111.230631)

17 Mutch NJ, Engel R, Uitte de Willige S, Philippou H \& Ariens RA. Polyphosphate modifies the fibrin network and down-regulates fibrinolysis by attenuating binding of tPA and plasminogen to fibrin. Blood 2010115 3980-3988. (https://doi.org/10.1182/blood-2009-11254029)

18 Hemker HC, Giesen P, AlDieri R, Regnault V, de Smed E, Wagenvoord R, Lecompte T \& Beguin S. The calibrated automated thrombogram (CAT): a universal routine test for hyper- and hypocoagulability. Pathophysiology of Haemostasis and Thrombosis 200232 249-253. (https://doi.org/10.1159/000073575)

19 Pieters M, Philippou H, Undas A, de Lange Z, Rijken DC, Mutch NJ \& Subcommittee on Factor XIII and Fibrinogen, and the Subcommittee on Fibrinolysis. An international study on the feasibility of a standardized combined plasma clot turbidity and lysis assay: communication from the SSC of the ISTH. Journal of Thrombosis and Haemostasis 201816 1007-1012. (https://doi.org/10.1111/jth.14002)

20 Casini A, Duval C, Pan X, Tintillier V, Biron-Andreani C \& Ariens RAS. Fibrin clot structure in patients with congenital dysfibrinogenaemia. Thrombosis Research 2016137 189-195. (https:// doi.org/10.1016/j.thromres.2015.11.008)

21 Longstaff C \& Subcommittee on Fibrinolysis. Development of Shiny app tools to simplify and standardize the analysis of hemostasis assay data: communication from the SSC of the ISTH. Journal of Thrombosis https://ec.bioscientifica.com https://doi.org/10.1530/EC-19-0429 (c) 2019 The authors Published by Bioscientifica Ltd
This work is licensed under a Creative Commons Attribution-NonCommercial-NoDerivatives 4.0 Internationab ticense.ifica com at $04 / 26 / 2023$ 12:01:05PM 
and Haemostasis 201715 1044-1046. (https://doi.org/10.1111/ jth.13656)

22 Eikelboom JW, Connolly SJ, Bosch J, Dagenais GR, Hart RG, Shestakovska O, Diaz R, Alings M, Lonn EM, Anand SS, et al. Rivaroxaban with or without aspirin in stable cardiovascular disease. New England Journal of Medicine 2017377 1319-1330. (https://doi. org/10.1056/NEJMoa1709118)

23 Lutsey PL, Folsom AR, Heckbert SR \& Cushman M. Peak thrombin generation and subsequent venous thromboembolism: the Longitudinal Investigation of Thromboembolism Etiology (LITE) study. Journal of Thrombosis and Haemostasis 20097 1639-1648. (https://doi.org/10.1111/j.1538-7836.2009.03561.x)

24 van Hylckama Vlieg A, Christiansen SC, Luddington R, Cannegieter SC, Rosendaal FR \& Baglin TP. Elevated endogenous thrombin potential is associated with an increased risk of a first deep venous thrombosis but not with the risk of recurrence. British Journal of Haematology 2007138 769-774. (https://doi.org/10.1111/j.13652141.2007.06738.x)

25 Lavigne-Lissalde G, Sanchez C, Castelli C, Alonso S, Mazoyer E, Bal Dit Sollier C, Drouet L, Juhan-Vague I, Gris JC, Alessi MC, et al. Prothrombin G20210A carriers the genetic mutation and a history of venous thrombosis contributes to thrombin generation independently of factor II plasma levels. Journal of Thrombosis and Haemostasis 20108 942-949. (https://doi.org/10.1111/j.15387836.2010.03773.x)

26 Byrnes JR \& Wolberg AS. Red blood cells in thrombosis. Blood 2017130 1795-1799. (https://doi.org/10.1182/blood-2017-03745349)

27 Hammer Y, Soudry A, Levi A, Talmor-Barkan Y, Leshem-Lev D, Singer J, Kornowski R \& Lev EI. Effect of vitamin D on endothelial progenitor cells function. PLOS ONE 201712 e0178057. (https://doi. org/10.1371/journal.pone.0178057)

Received in final form 6 October 2019

Accepted 14 October 2019

Accepted Preprint published online 15 October 2019 (c) 2019 The authors Published by Bioscientifica Ltd
This work is licensed under a Creative Commons Attribution-NonCommercial-NoDerivatives 4.0 Internationab bicense.ifica . com at 04/26/2023 12:01:05PM 